\title{
RETRACTED ARTICLE: The benefit of arthroscopically assisted therapy for concomitant glenohumeral injuries in patients with unstable lateral clavicle fractures
}

\author{
Tim Schwarting ${ }^{1} \cdot$ Philipp Lechler $^{1} \cdot$ Benjamin Bockmann $^{1} \cdot$ Florian Debus $^{1} \cdot$ \\ Ewgeni Ziring ${ }^{1} \cdot$ Michael Frink ${ }^{1}$
}

Received: 16 July 2015 / Accepted: 26 November 2015 / Published online: 12 December 2015

(C) European Society of Sports Traumatology, Knee Surgery, Arthroscopy (ESSKA) 2016

This article has been retracted at the request of the authors. The reason is that the authors have stated that the number of patients at time points investigated as well as data regarding pain levels and functional outcome are incorrect. They would like to express their regrets to the Editor-inChief and the whole Editorial Board.

The online version of this article contains the full text of the retracted article as electronic supplementary material.

Electronic supplementary material The online version of this article (doi:10.1007/s00167-015-3909-9) contains supplementary material, which is available to authorized users.

Michael Frink

michaelfrink@web.de

1 Center for Orthopaedics and Trauma Surgery, University

Hospital Giessen and Marburg, Baldingerstrasse,

35043 Marburg, Germany 